\title{
Letter from Beirut
}

After the horrifying murder of Dr. Malcolm Kerr, President of the American University of Beirut (AUB), it is not just the U.S. diplomats or the marines here in Beirut who feel terrorized-ordinary Americans feel it too, and so do the Lebanese and foreign residents of Ras-Beirut-that unique community abutting the AUB campus composed of middle-class Lebanese of every religious persuasion, as well as many American and Europeans. Those of us who were lucky enough to partake even occasionally in the stimulating ambience of AUB and Ras-Beirut now see it threatened as never before. The killing of Dr. Kerr, the continuing shelling and bombings, and the recent sharp deterioration of the Lebanese economy force one to wonder how long it can last.

Malcolm Kerr was born in Beirut, and his parents were both wellknown educators at AUB. He was accomplished in the Arabic language and a respected scholar of Lebanese history and politics as well as of Arab Society in general. Had he not been gunned down at the age of fifty-two, he could have served the university and Lebanon for two more decades. If anybody could pull AUB through the Lebanese crisis it surely would have been Malcolm Kerr. From all quarters have come warm tributes, the warmest, interestingly, from those most critical of American Middle East policy and the U.S. military involvement here. But being a "good American" was no protection. Indeed, his fairmindedness, evenhandedness, and popularity (in most but not all circles) perhaps made him an even more attractive target for those who want to destroy American influencecultural as well as political-in the region.

It is indicative of the poisoned political atmosphere here that at least a half-dozen contradictory hypotheses are circulating as to the identity of the murderers. There seems to be a general acceptance in East Beirut and among Maronite organizations that an Iranian-inspired "Islamic Jihad Organization" is responsible. Some also accuse the Amal movement and/or Syrian intelligence. Many people around West Beirut are convinced that it was the Lebanese Forces or Phalangists (many of whom were opposed to Kerr and to alleged Palestinian and "leftist" tendencies at AUB); others blame Israeli intelligence. Some on both sides suspect the Soviet K.G.B. Many feel that Dr. Kerr would be alive today if the U.S. Marines had not become involved in the Lebanese civil war. There is strong sentiment in the American community for a serious and thorough investigation of the crime by U.S. as well as by Lebanese authorities. 
Like so many in Middle East Studies, we at Georgetown were strongly influenced by Malcolm Kerr. Nearly every faculty member in the Center for Contemporary Arab Studies had some association with the late president. Our students know him from his writings as one of the acutest analysts of contemporary Arab and Middle Eastern politics. We will miss him, but AUB and Lebanon will miss him much more, for they they have lost a major asset in their struggle to survive the present crisis. Americans in general also have cause to mourn the killing of this excellent scholar and friend of the Arabs. At a time in which the historic Arab respect for America and American values is fast disappearing, the loss of Malcolm Kerr is a national tragedy as well.

MiCHAEL C. HudSON
Beirut, 21 January 1984

Adapted with permission from the Newsletter of the Center for Contemporary Arab Studies Georgetown University, Washington, D.C. 